\title{
Biogeociclos: Uma visão molecular das enzimas e dos mecanismos envolvidos nos ciclos dos elementos - Parte II
}

\author{
CARLA CARNEIRO ${ }^{1}$ E JOSÉ J.G. MOURA
}

\author{
Parte 2: Biogeociclo do Enxofre \\ Título corrente: Biogeociclos dos ele- \\ mentos
}

Palavras chave: Ciclos dos elementos, Azoto, Enxofre, Carbono, Hidrogénio

\section{Nota prévia}

A circulação dos elementos químicos no planeta é um processo complexo com muitas e variadas vertentes. Os vários ciclos elementares são muito mais do que simples reacções químicas. São em parte biológicos e em parte geoquímicos, pois envolvem a participação de microrganismos e estão associados a grupos de elementos metálicos. Uma variedade de enzimas e múltiplos transportadores electrónicos (que com estas interactuam) asseguram a catálise, passo a passo, por formação de intermediários chave.

Conforme se indicou na Parte I desta série de artigos, é objectivo rever aspectos estruturais dos enzimas envolvidos nos ciclos dos elementos. Os ciclos não são apresentados de modo exaustivo, mas procura-se pôr em evidência as partes dos ciclos para os quais há um conhecimento detalhado da estrutura tridimensional do biocatalisador envolvido. Mais ainda, são apresentadas hipóteses mecanísticas que resultam, muitas delas, da análise estrutural.

$\mathrm{O}$ artigo é dividido em 3 partes:

1 - Biogeociclo do AZOTO

2- Biogeociclo do ENXOFRE

3- Biogeociclo do CARBONO e HIDROGÉNIO

\section{O Ciclo do enxofre}

\subsection{Introdução}

Na natureza, os compostos de azoto e de enxofre são continuamente sintetizados, degradados e convertidos noutras formas. O metabolismo destes compostos tem muito em comum, pois ambos os elementos podem ser utilizados pelos microrganismos em vários estados de valência, desde estados mais reduzidos (amónia/sulfureto de hidrogénio) a estados mais oxidados (nitrato/sulfato). As formas reduzidas $\left(\mathrm{NH}_{3}\right.$ e $\mathrm{NO}_{2} / \mathrm{H}_{2} \mathrm{~S}$ e S ) podem ser utilizadas como doadores electrónicos na formação aeróbica de energia e na fixação de dióxido de carbono no escuro. As formas oxidadas $\left(\mathrm{NO}_{3}, \mathrm{NO}_{2}-\mathrm{SO}_{4}{ }^{2-}, \mathrm{SO}_{3}{ }^{2-}\right.$ ) servem como aceitadores electrónicos na respiração anaeróbia (Schlegel, 1981).

$\mathrm{O}$ sulfato, resultante da oxidação de $\mathrm{S}^{2}$, $\mathrm{S}$ ou $\mathrm{S}_{2} \mathrm{O}_{3}{ }^{2}$, é facilmente assimilável pela maioria dos organismos, contudo é está- vel e não reactivo, pelo que tem que ser activado antes de ser novamente utilizado, via adenilação, num processo que requer ATP. O passo de activação envolve a transferência da porção adenosina 5-fosforilo da molécula de ATP para o sulfato, formando um intermediário activado, a adenosina 5'-fosfosulfato (APS), de acordo com a equação:

$\mathrm{MgATP}+\mathrm{SO}_{4}{ }^{2-} \rightarrow \mathrm{MgPP}+\mathrm{APS}$

$\mathrm{Na}$ maioria dos organismos o intermediário APS é convertido no intermediário adenosina 3'-fosfato 5'-fosfosulfato (PAPS), de acordo com a seguinte equação:

$\mathrm{MgATP}+\mathrm{APS} \rightarrow \mathrm{MgADP}+\mathrm{PAPS}$

Ambas as formas, APS e PAPS (figura 1), são compostos com elevado potencial de transferência do grupo sulfato, devido à ligação anidrido mista ácido fosfórico-ácido sulfúrico, e disponibilizam assim o sulfato para posteriores reacções de transferência e redução. A importância da PAPS, como doador de grupos sulfidrilo na biossíntese de ésteres sulfurados, é análoga ao da ATP (doador de grupos fosfato) na biossíntese de ésteres fosfatados (Moura et al., 2002),

O ciclo do enxofre (figura 2) evidencia a interconversão do enxofre inorgânico nos vários estados de oxidação. A redu-

REQUIMTE, Departamento de Química, Faculdade de Ciências e Tecnologia, Universidade Nova de Lisboa, 2829-516 Monte de Caparica, Portugal Morada: Professor José J. G. Moura, Departamento de Química, Faculdade de Ciências e Tecnologia, Universidade Nova de Lisboa, Quinta da Torre, 2829 - 516 Monte de Caparica, Portugal. Tel: +351-21-2948382, Fax: +351-21-2948550, e-mail: jose.moura@dq.fct.unl.pt, www.dq.fct.unl.pt/bioin/

${ }^{1}$ Morada presente: Departamento de Sistemas e Informática, Escola Superior de Tecnologia, Instututo Politécnico de Setúbal, Rua Vale de Chaves, Estefanilha, 2910-761 Setúbal 
figura 1 Estrutura dos intermediários formados na activação do sulfato, via adenilação, adenosina $5^{\prime}$-fosfosulfato (APS) e adenosina 3'-fosfato 5'-fosfosulfato (PAPS).

ção assimilativa do sulfato a sulfureto é essencial na síntese de aminoácidos, proteínas e outros compostos sulfurados (ácido lipoíco, tiamina, biotina, coenzima A) e envolve a formação dos intermediários APS (passo 1) ou PAPS (passo 2). A via APS é comum aos organismos que realizam uma fotossíntese oxigénica (cianobactérias, algas e plantas), enquanto a via PAPS é utilizada por organismos que realizam uma fotossíntese anoxigénica (bactérias como Escherichia (E.) coli e fermentos). A redução dissimilativa é semelhante mas envolve apenas a formação do intermediário APS, que é reduzido a sulfito (MacRae et al., 2001, Moura et al., 2002).

O sulfito pode ser directamente reduzido a sulfureto, um processo envolvendo

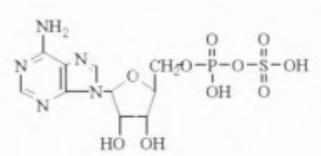

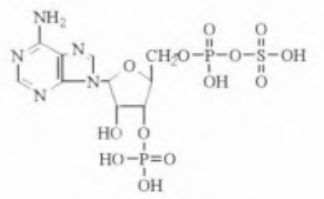

seis electrões, ou, alternativamente, a redução decorre em três passos, com formação de tritionato $\left(\mathrm{S}_{3} \mathrm{O}_{6}{ }^{2-}\right)$ e tiosulfato $\left(\mathrm{S}_{2} \mathrm{O}_{3}{ }^{2}\right)$, num processo denominado desulfuricação (respiração anaeróbia do sulfato) (Schlegel, 1981; Lampreia et al., 1994; Stroupe e Getzoff, 2001; Moura et al., 2002). Contrariamente às bactérias desnitrificantes, os organismos desulfuricantes, ana eróbios estritos com um metabolismo fermentativo, são incapazes de oxidar substratos orgânicos (lactato) a $\mathrm{CO}_{2}$ e $\mathrm{H}_{2} \mathrm{O}$, devido à falta dum ciclo do ácido cítrico (CAC) completo, pelo que excretam acetato (Schlegel, 1981; Lampreia et al., 1994; Stroupe e Getzoff, 2001).

Desulfuração é o processo de mineralização no qual os grupos mercapto, re- sultantes da decomposição anaeróbica da matéria orgânica, são libertados como sulfito. 0 sulfito formado pode então ser oxidado a sulfato; dos vários organismos que efectuam esta oxidação, apenas as bactérias quimiossintéticas acoplam a energia libertada à redução do dióxido de carbono (Schiff e Frankhauser, 1981; Schlegel, 1981; Lampreia et al., 1994).

\subsection{Caracterização molecular de enzimas envolvidas no ciclo do enxofre}

\subsubsection{Sulfurilase da adenosina trifosfato (ATPS) (passo 1)}

A sulfurilase da adenosina trifosfato (ATPS) catalisa o primeiro passo para assimilação do sulfato, de acordo com a seguinte equação:

$\mathrm{MgATP}+\mathrm{SO}_{4}{ }^{2-} \rightarrow \mathrm{MgPP}_{\mathrm{i}}+\mathrm{APS}$

Esta família de enzimas, isolada de uma variedade de organismos e com uma distribuição ubíqua, é consideravelmente heterogénea no que diz respeito à sequência de aminoácidos, massa molecular e organização das subunidades (Gavel et al., 1998). Contrariamente a outras ATPS, das quais não existe referência relativa à presença de metais, as

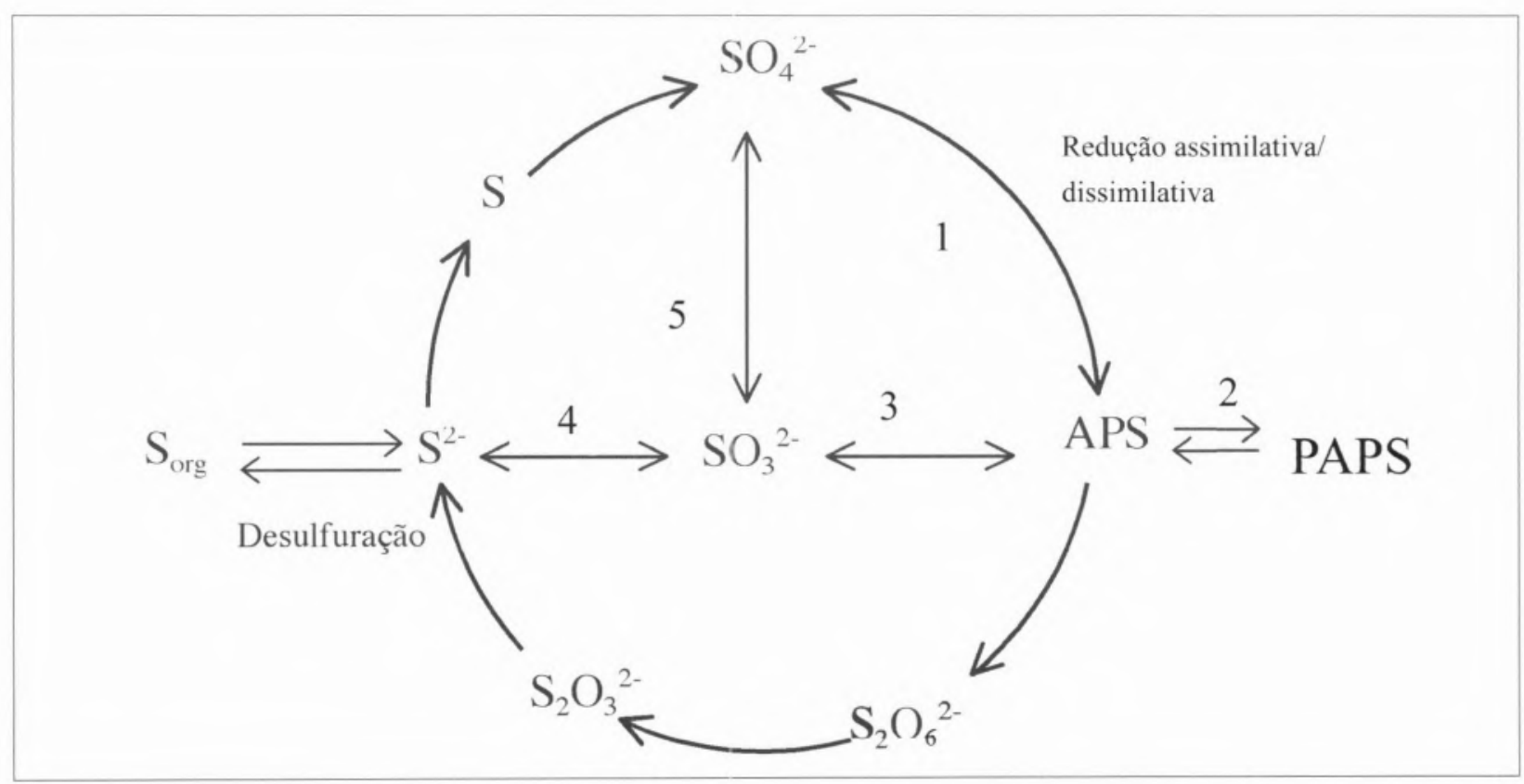

figura 2 Ciclo biogeoquímico do enxofre. A redução assimilativa do sulfato $\left(\mathrm{SO}_{4}{ }^{2}\right)$ a sulfito $\left(\mathrm{SO}_{3}^{2}\right)$ envolve a acção conjunta da ATPS (passo 1) e da cinase da APS (passo 2). O sulfito formado por catálise da APSR (passo 3) é então reduzido a sulfureto (S2-) por intermédio da aSIR (passo 4). A redução dissimilativa é semelhante, mas não envolve o passo 2 . O sulfureto proveniente da hidrólise do enxofre orgânico é oxidado a sulfito e este a sulfato por intermédio da SO (passo 5). 


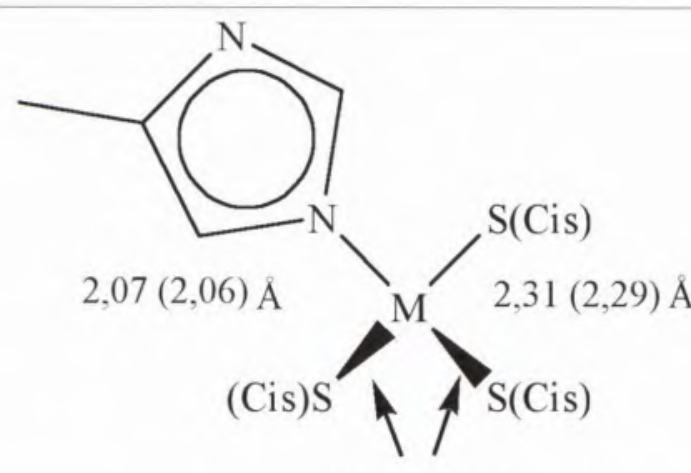

$2,31(2,29) \AA$ de Desulfovibrio (D.) desulfuricans ATCC 27774 e D. gigas, isoladas e caracterizadas recentemente, foram consideradas como metaloproteínas. São homotrímeros contendo um centro metálico mononuclear, de cobalto ou zinco, por subunidade, que surge alternativamente. Em ambos os centros, com uma geometria tetraédrica, o metal possui como ligandos três enxofres (cisteína) e um azoto (histidina) (figura 3). A presença do metal foi sugerida como factor essencial na manutenção da conformação cataliticamente activa (Gavel et al., 1998; Gavel et al., 2000).

As estruturas de Raios-X conhecidas para as ATPS de Penicillium ( $P$.) chrysogenum e Saccharomyces cerevisiae são idênticas e apresentam muitas semeIhanças com transferases de nucleotídeo (em termos de enrolamento e arquitectura do sítio activo), no entanto, considerando o modo particular como ligam a ATP, estas definem uma nova classe de enzimas (MacRae et al., 2001; Ullrich et al., 2001). A estrutura recentemente publicada para o simbionte do verme hidrotermal Riftia pachyptila revela um dímero e não um hexamero podendo reflectir a forma ancestral das ATPS homo-oligoméricas (Beynon et al., 2001).

A ATPS de $P$. chrysogenum é um oligómero composto por seis subunidades idênticas de $63 \mathrm{kDa}$ e pode ser considerada como um dímero de tríades (figura $4 A$ ). Dentro de cada tríade, o domínio alostérico de uma subunidade interactua com o domínio catalítico de outra subunidade, de modo que cada subunidade interactua com outras duas, para além de outras interacções adicionais na interface da tríade. A estabilidade do hexâmero é determinada pelas interac- figura 3 Estrutura proposta para o local de coordenação do cobalto e zinco para as ATPS de D. desulfuricas ATCC 27774 e de D. gigas. $\mathrm{M}$ representa o $\mathrm{Co}$ ou $\mathrm{Zn}$, os comprimentos de ligação são valores médios, entre parêntesis são apresentados os valores para o Co (Adaptado de Gavel et al., 1998).

ções de cada subunidade com outras quatro, particularmente por interacções entre o "dímero do domínio alostérico", que permitem uma transição alostérica concertada. Os resíduos Arg199, His203 e His206 são essenciais para a actividade da sulfurilase (MacRae et al., 2001).

Cada subunidade é composta por três domínios (figura 4B): o N-terminal, cuja função é desconhecida, o central catalítico e o C-terminal alostérico (local de ligação da PAPS, inibidor alostérico). 0 $\mathrm{N}$-terminal é constituído por um barril parcial de folha $\beta$ rodeada de hélices $\alpha$. 0 domínio central, empacotado com o anterior, apresenta um enrolamento de "Rossmann", tipicamente observado nas hidrogenases. O C-terminal está separado dos anteriores por um pequeno trecho e apresenta uma topologia mista em hélice $\alpha /$ folha $\beta$, semelhante à cinase da
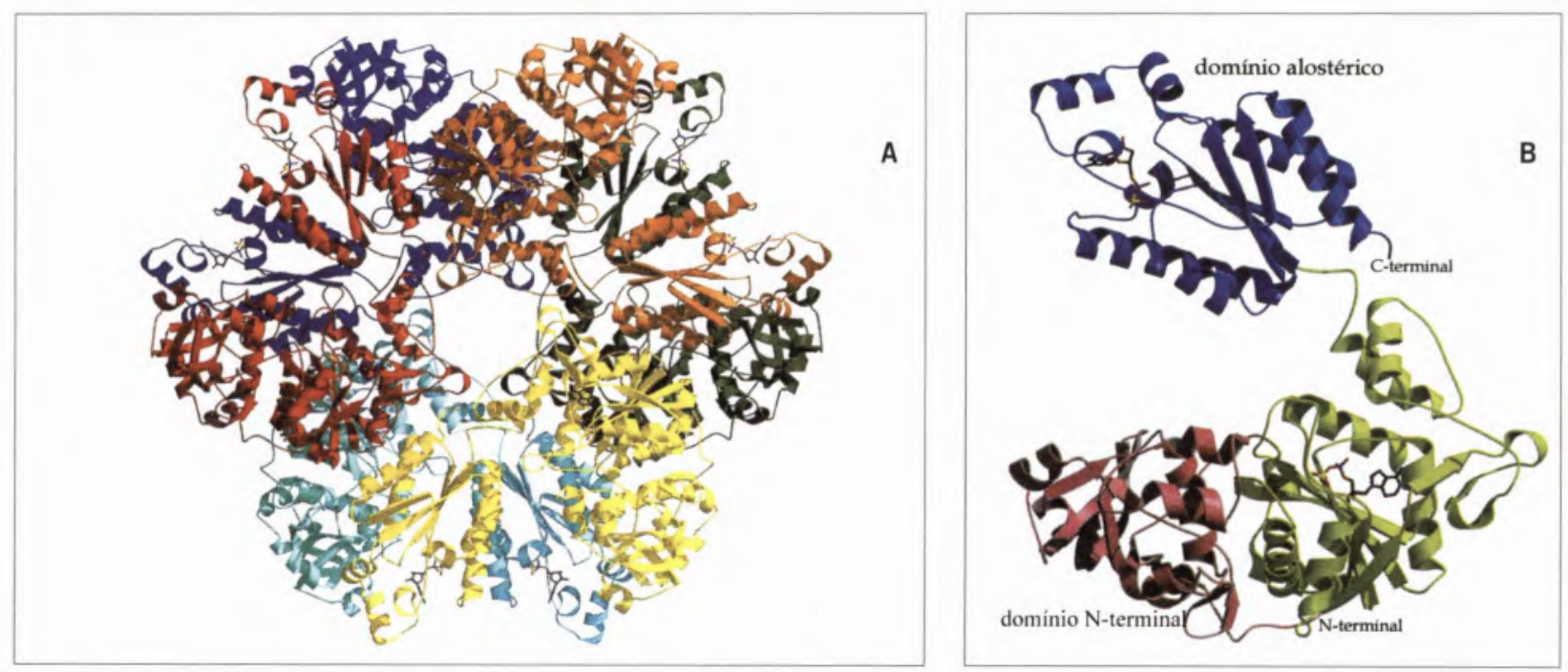

figura 4 (A) Representação esquemática do hexâmero e (B) representação esquemática do nomónero da ATPS de P. chrysogenum (Adaptado de MacRae et al., 2001). 
figura 5 Representação esquemática dos residuos que interactuam com o substrato na ATPS de P. chrysogenum (Adaptado de MacRae et al., 2001).

APS; no entanto, não apresenta actividade de cinase, provavelmente pelas alterações na região do "loop P" e substituição de uma leucina por um aspartato (Asp61), que interactua com o complexo MgATP (MacRae et al., 2001).

O domínio catalítico liga uma única molécula de APS no topo da região em folha $\beta$ (figura 5). O sítio catalítico está acessivel apenas a partir do meio exterior, localiza-se numa cavidade contígua ao solvente exterior e não da cavidade central. 0 substrato é estabilizado por ligações por pontes de hidrogénio com vários resíduos da cadeia polipeptídica, definindo um padrão 197QXRN200, na ligação da porção fosfosulfato e um padrão 203HXXH206, na ligação do nucleosídeo (porção adenilil). Uma valina (Val333) funciona como doador protónico (MacRae et al., 2001)

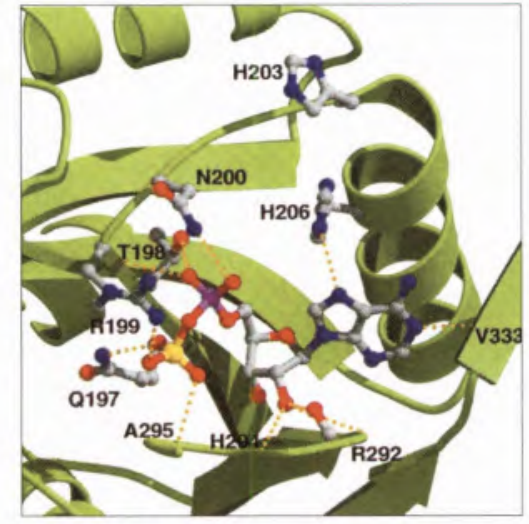

A existência de um fosso que liga o domínio catalítico de uma tríade ao domínio alostérico da outra tríade pode ser reminiscência de uma actividade bifuncional como sintetase da PAPS. A disposição de cada monómero de tríades na formação do hexâmero permite definir dois tipos de dímeros (figura 6): o dímero do domínio alostérico e o dímero do domínio catalítico, com uma rotação de cerca de 350 entre si. A interface do dímero do domínio alostérico é estabilizada por uma ligação salina (Arg457 e Glu443) e vários resíduos hidrofóbicos. A transição alostérica pode ser transmitida por uma arginina (Arg515) de um dos domínios alostéricos que interactua com um aspartato (Asp111) do N-terminal adjacente. 0 dímero do domínio catalítico, menos extenso, é estabilizado por empacotamento das hélices a. Deste modo, cada subunidade está em contacto com quatro das subunidades do hexâmero, favorecendo a transmissão das alterações introduzidas por ligação do substrato, essencial no funcionamento de enzimas alostéricas (MacRae et al., 2001).

Recentemente, a obtenção de uma estrutura de Raios-X para a ATPS de levedura revelou que, apesar desta não apresentar propriedades alostéricas, as características multidomínio são muito semelhantes, mesmo relativamente à topologia do sítio activo e dos residuos "activos". Porém, o desconhecimento, até ao momento, das coordenadas impede comparações adicionais (MacRae et al., 2001).

\subsubsection{Redutase da adenosina $5^{\prime}$ - fosfosulfato (APSR) (passo 3)}

A redutase da adenosina $5^{\prime}$-fosfosulfato (APSR) catalisa a reacção reversivel de redução de APS a sulfito, de acordo com a seguinte equação:

$$
\mathrm{APS}+2 \mathrm{e}-\stackrel{\leftarrow}{\rightarrow} \mathrm{AMP}+\mathrm{SO} 32-+2 \mathrm{H}+
$$

Esta enzima encontra-se largamente distribuída em bactérias redutoras de sulfato e outros organismos relacionados. Um estudo detalhado das propriedades bioquímicas e espectroscópicas de várias APSRs foi apresentado e revisto por Lampreia et al., 1994). Estes estudos conduzidos por RPE em particular permitiram antecipar uitas das propriedades estruturais posteriormente revela-
A

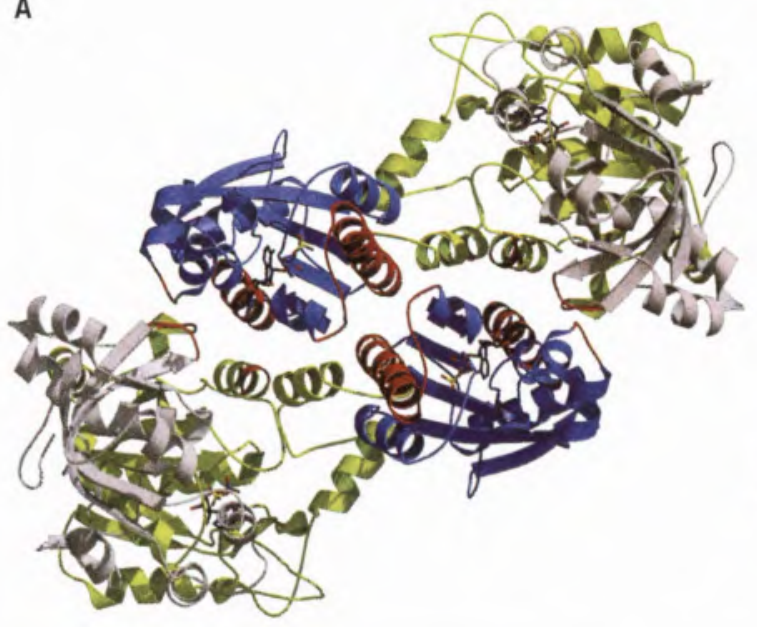

B

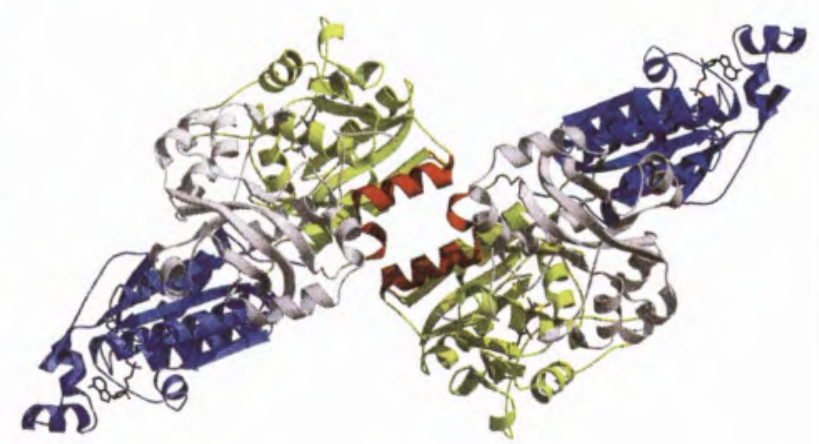

figura 6 (A) Representação do dímero do domínio alostérico e (B) representação esquemática do dímero do dominio catalítico da ATPS de P. chrysogenum (Adaptado de MacRae et al., 2001). 


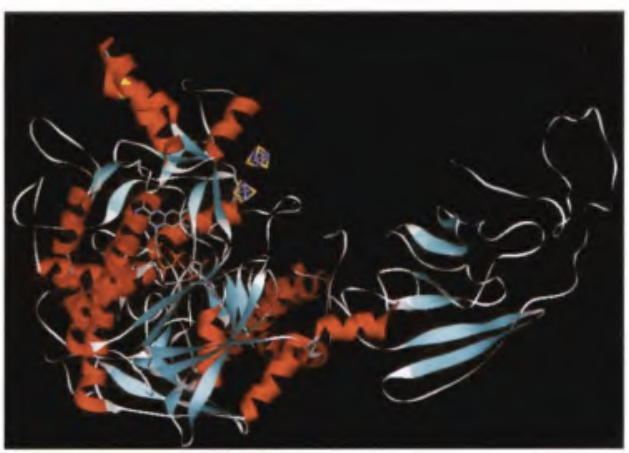

figura 7 Representação esquemática da APSR de Arch. fulgidus (Adaptado de Fritz et al., 2002).

das. Estas enzimas contêm em geral um grupo FAD (que participa directamente na interacção com o substrato) e dois centros ferro-enxofre.

A APSR de Archaeoglobus (Arch.) fulgidus (figura 7) é um heterodímero $\alpha \beta$ com uma massa molecular de $95 \mathrm{kDa}$; a subunidade $\alpha$ ( $75 \mathrm{kDa}$ ) possui uma molécula de FAD não covalentemente ligada e a subunidade $\beta$ (20 kDa) contém dois centros de [4Fe-4S], semelhantes aos das ferredoxinas (Roth et al., 2000; Fritz et al., 2002). É semelhante à enzima de D. desulfuricans ATCC 27774 , ambas citoplasmáticas; enquanto a de D. termophilus está associada à membrana (Lampreia et al., 1994; Fritz et al., 2002).

As estruturas de Raios- $X$ obtidas para a APSR de Arch. fulgidus, para o estado reduzido e com o sulfito ligado, permitiram estabelecer, por formação do aducto FAD-sulfito, que a molécula de FAD é o sítio activo. Os centros de ferro-enxofre participam na transferência electrónica (de dois electrões), a partir dum doador ainda desconhecido; um triptofano $(\operatorname{Trp} \beta 48)$ facilita a transferência electrónica entre o agregado I e a molécula de FAD. O heterodímero, com uma forma elipsoidal compacta, revela que a parte globular da subunidade $\beta$ está inserida numa cavidade superficial da subunidade $\alpha$. A sua longa cauda envolve a subunidade a, contribuindo para a estabilidade do dímero (Fritz et al., 2002).

A subunidade $\alpha$, a subunidade catalitica, pode ser dividida em três domínios: o de ligação da molécula de FAD e os domínios helicoidal e "em chapéu", num arranjo semelhante ao encontrado na família das redutases do fumarato. A molécula de FAD, localizada no interior da molécula (a cerca de 30 Å da superfície), expõe apenas o átomo de azoto N5 do anel de isoaloxazina ao solvente. $\mathrm{O}$ anel de isoaloxazina é estabilizado por vários resíduos (Asn74, Trp234, Leu70), numa conformação em borboleta, que favorece os estados reduzido e com o sulfito ligado (Fritz et al., 2002).

O canal que dá acesso ao sítio activo é definido pela interface entre os domínios de ligação do FAD e "em chapéu" e alberga resíduos carregados (Arg $\alpha 83$, Lis $\alpha 281$, Lis $\alpha 283$, Arg $\alpha 317$ ), envolvidos na selecção de iões que funcionam como substrato. Adicionalmente, o substrato é estabilizado por ligações por pontes de hidrogénio com um resíduo de asparagina (Asna74) e interacções salinas com outros residuos carregados (Trpo234, Argo265, Hisa398).

A subunidade $\beta$ pode ser também dividida em três domínios: a topologia do primeiro é semelhante à das ferredoxinas bacterianas e alberga os dois centros de $[4 \mathrm{Fe}-4 \mathrm{~S}]$ que distam cerca de

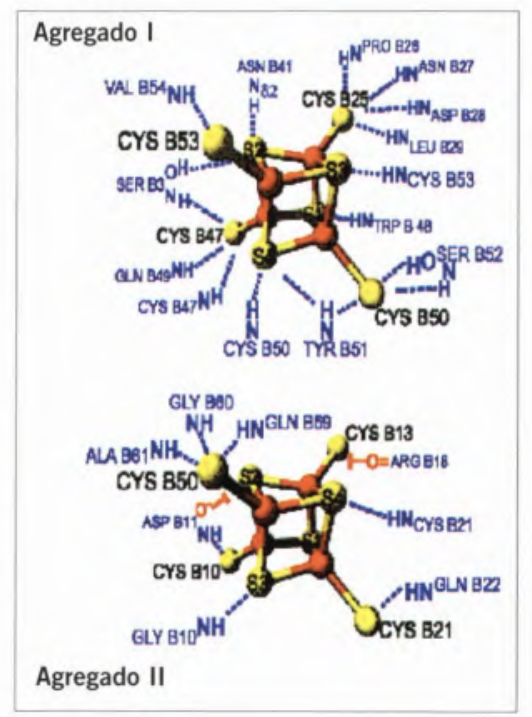

9,7 Å. Estes agregados (figura 8), cubanos distorcidos, estão coordenados por quatro cisteínas e exibem potenciais redox significativamente distintos, em consequência do diferente ambiente proteico que os rodeia; o aumento considerável do número de interacções polares no agregado I e a matriz proteíca, comparativamente com o agregado II, pode ser o factor de modelação destes potenciais. O segundo domínio, que constitui a interface das subunidades, é composto por três folhas $\beta$ antiparalelas e o terceiro domínio, o C-terminal, forma uma cauda que envolve a subunidade a, aumentando desde modo a área de contacto entre as duas subunidades (Fritz et al., 2002).

O ciclo catalítico (figura 9) tem início com a redução da molécula de FAD (a $\mathrm{FADH}_{2}$ ), a partir do doador fisiológico desconhecido, via agregado II (adjacente à superfície) e agregado I. A subsequente ligação da molécula de APS, por ataque nucleofílico do átomo de azoto N5 da molécula de $\mathrm{FADH}_{2}$ ao enxofre da

figura 8 Representação esquemática dos centros de [4Fe-4S] da APSR de Arch. Fulgidus (Adaptado de Fritz et al., 2002). 
figura 9 Mecanismo de catálise da APSR de Arch. fulgidus (Adaptado de Fritz et al., 2002)

APS (A) forma 0 aducto FAD-APS (B), estabilizado por interacções electrostáticas com a cadeia polipeptídica. Uma molécula de água da vizinhança, que actua como aceitador de protões do N5, favorece a formação deste intermediário covalente, que se decompõe espontaneamente em adenosina monofosfato (AMP) e o sulfito é libertado. Dois resíduos carregados positivamente desempenham um papel fundamental neste ciclo: a Arg 265 na ligação de ambos os grupos, fosfato e sulfato, da molécula de APS e a His 3398 que, para além da estabilização do substrato, por ligação por ponte de hidrogénio, pode funcionar como doador de protões durante a clivagem (Fritz et al., 2002).
A
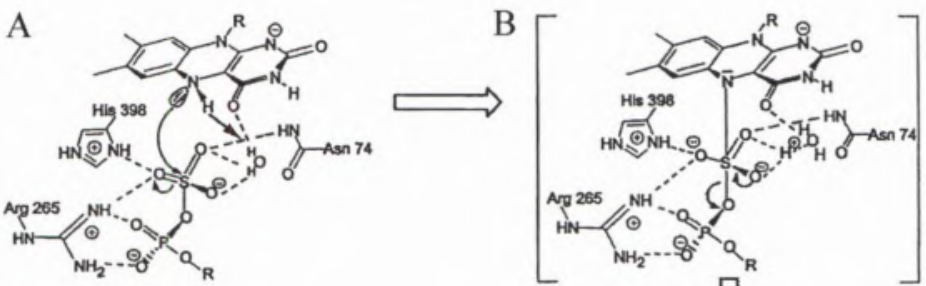

D

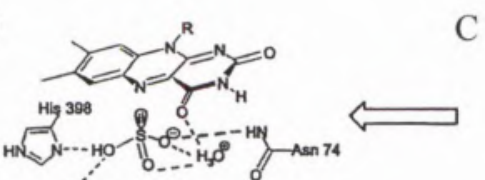

C

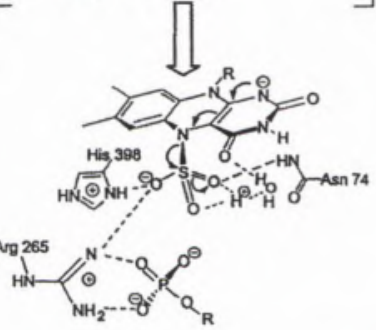

\subsubsection{Redutase do Sulfito (SiR) (passo 4)}

A redutase do sulfito $(\mathrm{SiR})$ catalisa a reacção de redução do sulfito a sulfureto, de acordo com a seguinte equação:

$$
\mathrm{SO} 32-+6 \mathrm{H}++6 \mathrm{e}-\rightarrow \mathrm{S} 2-+3 \mathrm{H} 2 \mathrm{O}
$$

Reduz igualmente o nitrito a amónia, utilizando electrões provenientes do NADPH dissociável ou de flavinas coordenadas (Stroupe e Getzoff, 2001).

Existem duas classes de redutases do sulfito que diferem na sua função e composição, mas ambas possuem um sirohemo acoplado a um centro de [4Fe-4S], por uma cisteína endógena. A redutase do sulfito dissimilativa (dSiR) é um heterotetrâmero $(\alpha 2 \beta 2)$ que catalisa o último passo da respiração anaeróbia, convertendo o sulfito em sulfureto ou alternativamente via tritionato. A redutase do sulfito assimilativa (aSiR) incorpora o enxofre em aminoácidos (Stroupe e Getzoff, 2001).

A aSiR de $E$. coli é um complexo $\alpha 8 \beta 4$ de 784 kDa e cada subunidade da holoenzima possui uma função única. Cada subunidade maior (SiRFP), de 66 $\mathrm{kDa}$, liga uma molécula de $F A D$, uma molécula de FMN e uma molécula dissociável de NADPH e funciona como doador electrónico. A SiRFP é semeIhante à redutase do $P_{450}$. Na subunidade menor (SiRHP), de 64 kDa, o sítio catalítico, localizado no lado distal do sirohemo, está acoplado por uma cisteína, a um centro de [4Fe-4S]. Alguns re-

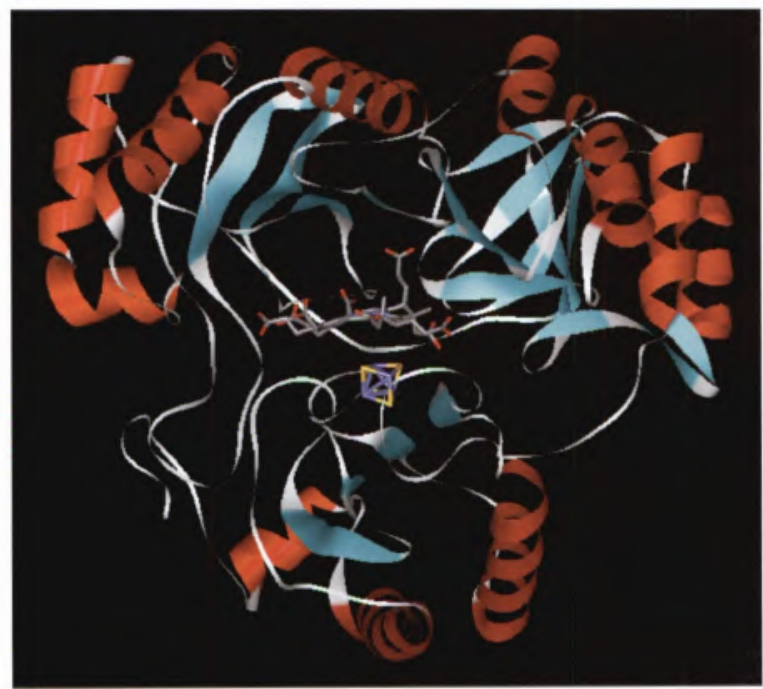

figura 10 Representação esquemática da SiRHP da aSiR de E. coli. Os co-factores estão representados por modelos "stick and ball" (Adaptado de Stroupe e Getzoff, 2001).

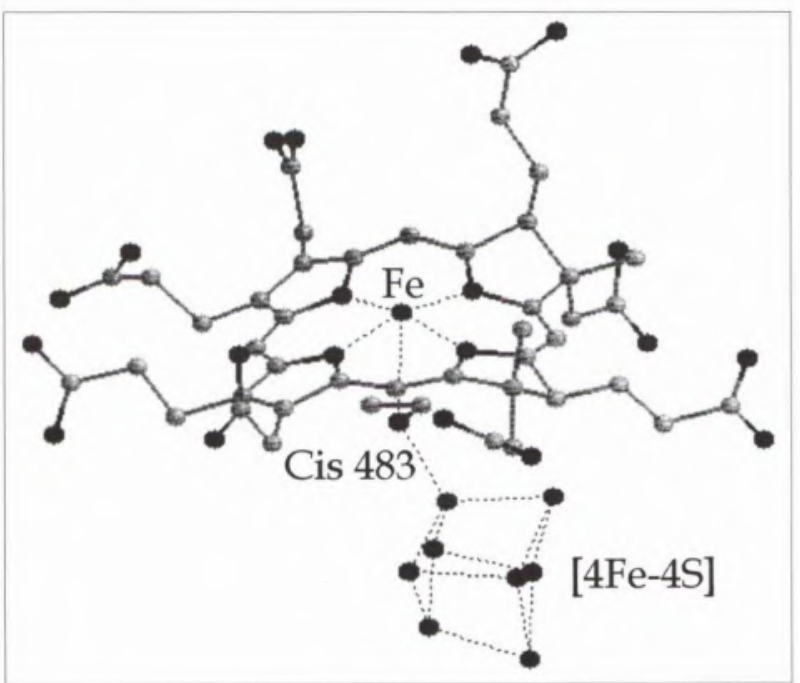

figura 11 Representação esquemática dos co-factores da SiRHP de E. coli (Stroupe e Getzoff, 2001) 


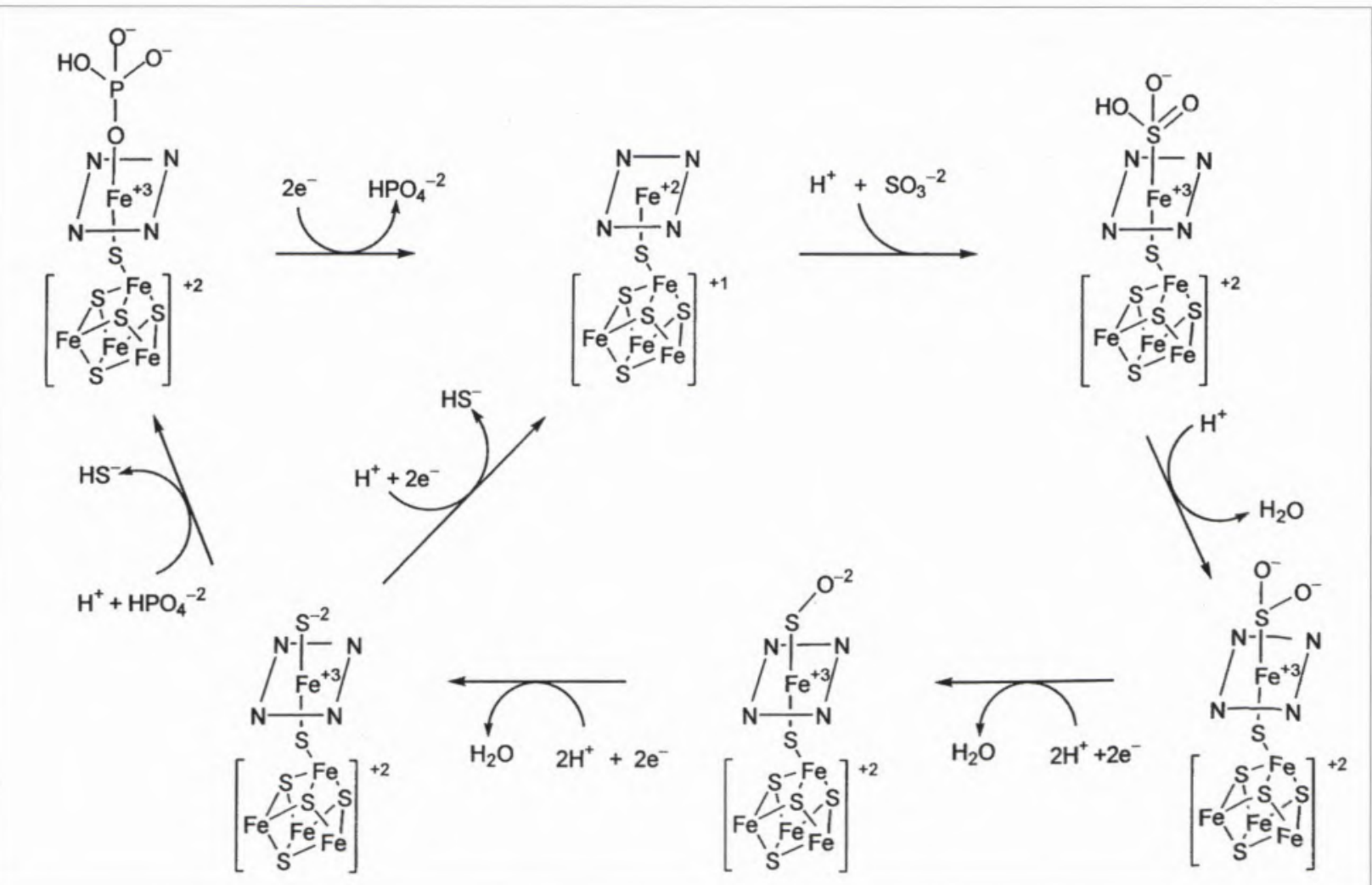

figura 12 Mecanismo de catálise proposto para a SiR de E. coli (Stroupe e Getzoff, 2001).

síduos carregados (Arg83, Arg153, Lis215, Lis217) conferem uma densidade positiva ao sítio activo, favorecendo a ligação do substrato (Stroupe e Getzoff, 2001).

\section{A subunidade catalítica da SiRHP}

A SiRHP (figura 10) é uma proteina trilobular com os co-factores ligados na interface dos três domínios. 0 domínio 1 , em forma de paraquedas, é composto por duas folhas $\beta$ antiparalelas, que ligam uma capota de hélices $\alpha$, expostas ao solvente, a um "loop" em forma de gancho de cabelo. Os domínios 2 e 3 são compostos por cinco folhas $\beta$, rodeadas por três hélices $\alpha$, em contacto com o solvente. A interface dos domínios é formada essencialmente por ligações salinas (Stroupe e Getzoff, 2001).

Os resíduos do domínio 2, carregados positivamente, criam uma cavidade que permite a ligação do substrato, no lado distal do sirohemo, e que na sua ausência, coordena uma molécula de fosfato por um dos oxigénios. Dois "loops" do domínio 3 fornecem as cisteínas que coordenam o centro de [4Fe-4S], protegendo-o simultaneamente do contacto com o solvente. O segundo "loop" fornece a cisteína (Cis483) que liga em ponte o centro de ferro-enxofre $\left(\mathrm{Fe}_{4}\right)$ e 0 sirohemo, pelo que os co-factores se encontram relativamente próximos (cerca de $5 \AA$ ) (figura 11). 0 sirohemo está ligeiramente dobrado, sugerindo que existe mais do que um percurso electrónico ou esta distorção favorece a aproximação dos dois co-factores. Adicionalmente, estes "loops" têm duas funções: permitem o acoplamento da flavoproteína e ajustam o potencial redox do centro de ferro-enxofre (Stroupe e Getzoff, 2001).

A redução do sulfito (figura 12), que envolve seis electrões, decorre sem libertação de intermediários, apesar das grandes alterações na geometria do substrato. Dois electrões, provenientes da flavoproteína, reduzem ambos os cofactores, com consequente libertação do fosfato (que ocupa o sítio activo na ausência do substrato). O sulfito, com um dos seus oxigénios protonados, ligase ao lado distal do sirohemo através do enxofre, enquanto que a Arg153 é deslocada da sua posição original. Ligações por pontes de hidrogénio, com uma molécula de água existentes na cavidade, estabilizam o substrato ligado. Um segundo protão é doado por uma cadeia lateral da proteína (ou por moléculas de água), sai uma molécula de água, mas o intermediário sulfurado reduzido permanece ligado à SiRHP. Por repetição do ciclo anterior, a Arg153 retorna à sua posição original e o intermediário sulfurado reduzido continua ligado; o seu oxigénio estabelece uma ligação, por ponte de hidrogénio, com uma molécula de água. Um novo ciclo (de dois electrões e dois protões) sem alterações na arginina, origina a saída da terceira molécula de água e o intermediário reduzido mantém-se ligado; finalmente, a entrada de um protão origina a libertação do produto final $\left(\mathrm{SH}^{-}\right)$ou um fosfato liga-se, deslocando-o. A flexibilidade do sítio activo, por participação activa da Arg153, e as alterações conformacionais no "loop", induzidas pela ligação do substrato, sugerem que a catálise, rápida e eficiente, está relacionada com a ordem 
figura 13 Representação esquemática da SO de figado de galinha. Os co-factores estão apresentados por modelos "stick and ball" (Adaptado de Kisker, 2001).

que se gera no sítio activo por ligação do substrato (Stroupe e Getzoff, 2001).

\subsubsection{Oxidase do sulfito (SO) (passo 5)}

A oxidase do sulfito ( $\mathrm{SO}$ ) catalisa a oxidação do sulfito a sulfato, a reacção terminal na degradação dos aminoácidos sulfurados (cisteína e metionina), de acordo com a seguinte equação:

$$
\mathrm{SO}_{3}{ }^{2+}+\mathrm{H}_{2} \mathrm{O} \rightarrow \mathrm{SO}_{4}{ }^{2+}+2 \mathrm{H}^{+}+2 \mathrm{e}^{-}
$$

Desempenha igualmente um papel importante na detoxificação do sulfito e do dióxido de enxofre fornecido exogenamente (Kisker, 2001).

As enzimas de molibdénio podem ser genericamente agrupadas em duas classes: a primeira das nitrogenases, nas quais o molibdénio incorpora um centro multinuclear, e a das enzimas de molibdénio mononucleares, tais como a oxidase da xantina, a redutase do dime-

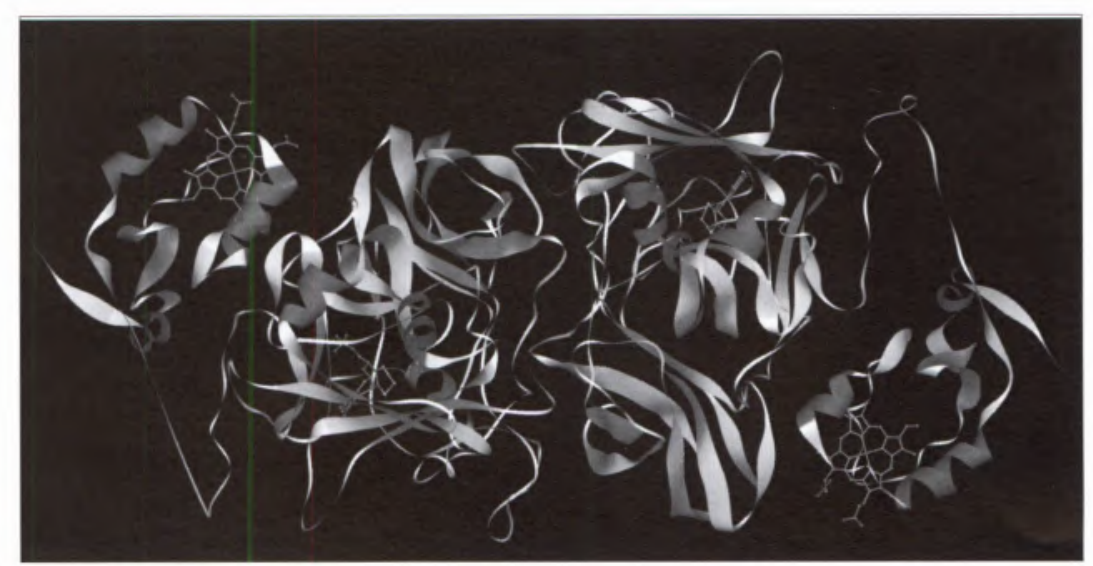

tilo sulfóxido (DMSO), a desidrogenase do formato e a oxidase do sulfito. No entanto, com base em dados cristalográficos, e tendo em conta a estrutura do centro de molibdénio, podem considerar-se três familias: (1) a família da oxidase da xantina, (2) a família da redutase do DMSO e (3) a família da oxidase do sulfito. Actualmente, são conhecidas estruturas de Raios-X para cada uma das famílias: a oxidoredutase do aldeído de $D$. gigas pertence à família da oxidase da xantina; as redutases do DMSO de Rhodobacter ( $R$.) capsulatus e de $R$. sphaeroides e a desidrogenase do formato de $E$. coli pertencem à segunda família e a oxidase do sulfito de fígado de galinha à família da oxidase do sulfito (Romão et al., 1997).

A oxidase do sulfito $(\mathrm{SO})$ de fígado de galinha, é um homodímero localizado no espaço intermembranar mitocondrial. Cada subunidade, com cerca de
53 kDa, contém um co-factor de molibdénio, uma pterina de molibdénio (MPT), ligado a um domínio C-terminal extenso e um pequeno domínio $\mathrm{N}$-terminal que alberga um hemo $b_{5}$, ligado de um modo não covalente com uma coordenação bis-histidina. 0 co-factor de molibdénio é o sítio catalítico que transfere os electrões para o hemo $b_{5} \mathrm{e}$ daí para um citocromo $c$. Uma cisteína (Cis185) coordenada ao molibdénio é essencial para a catálise e uma arginina (Arg138) está envolvida na transferência electrónica entre os dois co-factores (Kisker, 2001).

Cada monómero, com uma topologia mista em hélice $\alpha /$ folha $\beta$, está dividido em três domínios. 0 domínio I ( $\mathrm{N}$-terminal) é estruturalmente semelhante ao hemo $b_{5}$ de cavalo; compreende três foIhas $\beta$ antiparalelas, rodeadas por duas folhas $\beta$ pequenas, e seis hélices a definindo uma cavidade. $O$ hemo $b_{5}$, que

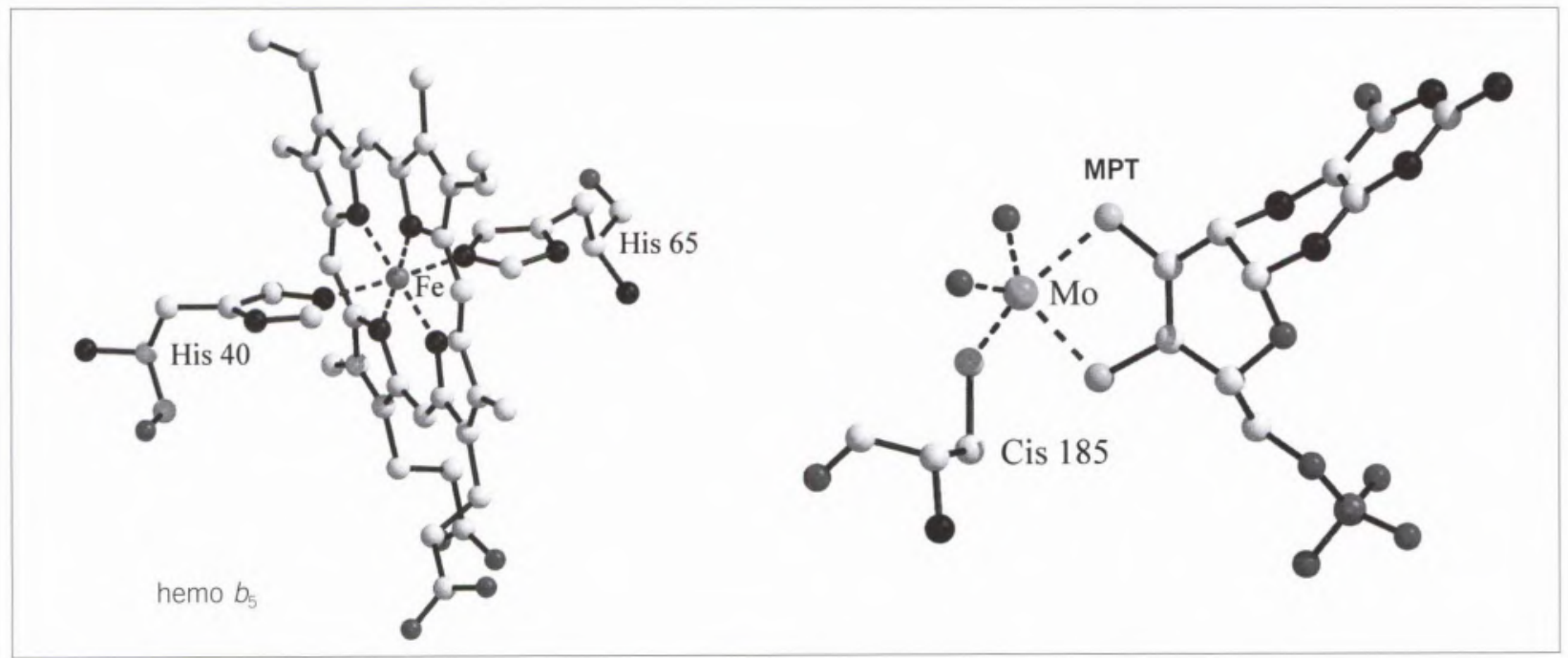

figura 14 Representação esquemática dos co-factores da SO de figado de galinha (Adaptado de Kisker, 2001). 
apresenta, como ligandos axiais, duas histidinas (His40 e His65), está localizado no fundo desta cavidade, protegido do solvente. 0 domínio II contém 13 cordões $\beta$, organizados em três folhas $\beta$ e nove hélices $\alpha$, cuja disposição não apresenta semelhanças com outras estruturas. Este pode ser subdividido em três regiōes e alberga, na parte central, o co-factor de molibdénio. O C-terminal, domínio III, contém sete cordões $\beta$ dispostos em duas folhas $\beta$ antiparalelas, formando um motivo em "Greek-key"; esta topologia é homóloga à encontrada no subtipo $\mathrm{C} 2$ da superfamília das imunoglobulinas (Kisker, 2001).

A forma alongada da SO (figura 13), resultado de uma disposição de topo entre os domínios III de cada monómero, é responsável pela grande distância entre os dois co-factores (32 Å). Apesar do plano de simetria existente na molécula, os dois hemos $b_{5}$ adoptam orientações diferentes, relativamente ao centro da molécula (estão rodados cerca de $5^{\circ}$ ). A interface do dímero é estabilizada por ligações por pontes de hidrogénio e pontes salinas, enquanto que as interacções entre os domínios | e || são predominantemente de natureza hidrofóbica (Kisker, 2001).

A molibdopterina (MPT), localizada no interior do domínio II, é estabilizada por inúmeras ligações por pontes de hidrogénio com os resíduos deste domínio. 0 molibdénio, com uma geometria em pirâmide quadrangular, é pentacoordenado (figura 14); um grupo oxo terminal ocupa a posição axial, enquanto que as posições equatoriais são ocupadas por três enxofres e um segundo grupo oxo; dois dos enxofres são os ditiolenos da pterina e o terceiro provém de uma cisteína (Cis185). Dos dois ligandos oxo, apenas 0 equatorial participa na catálise, funcionando como ponte entre o sulfito e o molibdénio; o ligando axial é espectador (Kisker, 2001).

No sítio activo, três argininas (Arg138, Arg190 e Arg450), Trp204, Tir322 e a Lis202 formam uma cavidade carregada positivamente, ideal para ligaçâo de aniões, o substrato, sulfito, e o produto, sulfato. Todos os átomos de oxigénio do sulfato estabelecem ligações por pontes de hidrogénio com estes resíduos (Kisker, 2001).

$\mathrm{O}$ meio ciclo redutivo compreende a redução do molibdénio, Mo(VI) a Mo(IV), enquanto o sulfito é oxidado a sulfato. A catálise é iniciada pelo ataque do par electrónico isolado, do sulfito ao ligando oxo equatorial; o sulfato é libertado do sítio activo e um hidroxilo do solvente preenche a posição de coordenação do molibdénio. 0 meio ciclo oxidativo, necessário para regenerar o centro dioxo, compreende uma transferência electrónica intramolecular, do molibdénio para o hemo $b_{5}$, e deste para um citocromo c. Uma segunda transferência electrónica, com concomitante desprotonação do hidroxilo ligado ao molibdénio, regenera a forma completamente oxidada, Mo(VI) (Kisker, 2001).

A grande distância existente entre os cofactores pode ser obviada, considerando a adopção de uma conformação diferente, por parte do domínio do hemo b5, facilitada pela região fléxivel que liga os domínios dos dois co-factores, e num percurso electrónico que envolve a Arg138 (Kisker, 2001).

\section{Agradecimentos}

Autores agradecem ao PRAXIS e COST apoio financeiro. Um agradecimento aos grupos de Bioinorgânica, Biofísica de Proteínas e Cristalografia de Proteinas do $C Q F B / D Q / F C T / U N L$ por muitas contribuições. Ao Jorge Pereira pela ajuda na obtenção de inúmera figuras.

\section{Bibliografia}

- Beynon, J.D., MacRae, I.J., Huston, S.L., Nelson, D.C., Segel, I.H., Fisher, A.J. (2001) "Crystal structure of ATP sulfurylase from the bacterial symbiont of the hydrotermal vent tubeworm Riftia pachyptila", Biochem., 40, 14509-14517

- Fritz, G., Roth, A., Schiffer, A., Büchert, T., Bourenkov, G., Bartunik, H.D., Huber, H., Stetter, K.O., Kroneck, P.M.H., Ermler, U.
(2002) 'Structure of adenylylsulfate reductase from the hyperthermophilic Archaeog/o-

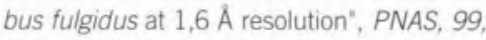
1836-1841

- Gavel, O.Y., Bursakov, S.A., Calvete, J.J., George, G.N., Moura, J.J.G., Moura, I. (1998) "ATP sulfurylases from sulfate reducing bacteria of the genus Desulfovibrio. A novel metalloprotein containing cobalt and zinc*, Biochem., 37, 16225-16232

- Kisker, C. (2001) "Sulfite oxidase" in Handbook of Metalloproteins, (A. Messerschmidt, R. Huber, T. Poulos, K. Wieghardt, Eds), Vol 2, pp 1121-1135, John Wiley \& Sons, LTD

- Lampreia, J., Pereira, A.S., Moura, J.J.G. (1994) "Adenylylsulfate reductases from sulfate-reducing bacteria" in Methods in enzymology (H.D. Peck, Jr., J. LeGall, Eds), Vol 243, pp 241-260, Academic Press

- MacRae, I.J., Segel, I.H., Fisher, A.J. (2001) "Crystal structure of ATP sulfurylase from Penicillium chrysogenum: insights into the alIosteric regulation of sulfate assimilation", Biochem., 40, 6795-6804

- Moura, J.J.G., Bursakov, S.A., Gaavel, O., Moura, I. (2002) Encyclopidea of Catalysis, John Wiley and Sons, Inc.

- Romão, M.J., Knäblein, J., Huber, R., Moura, J.J.G. (1997) "Structure and function of molybdopterin containing enzymes", Prog. Biophys. Molec. Biol., 68, 121-144

- Schiff, J.A., Fankhauser, H. (1981) "Assimilatory sulfate redution" in Biology of inorganic nitrogen and sulfur $(H$. Bothe, $A$. Trebst Eds), Vol 1, pp 153-168, SpringerVerlag

- Schlegel, H.G. (1981) "Microorganisms involved in the nitrogen and sulfur cycles" in Biology of inorganic nitrogen and sulfur $(\mathrm{H}$. Bothe, A. Trebst Eds), pp 3-12, Springer-Verlag

- Schmid, B., Chiu, H.-J., Ramakrishnan, V., Howard, J.B., Rees, D.C. (2001) "Nitrogenase" in Handbook of metalloproteins (A. Messerschmidt, R. Huber, T. Poulos, K. Wieghardt, Eds), Vol 1, pp 1025-1036, John Wiley \& Sons, LTD

- Stroupe, M.E., Getzoff, E.D. (2001) "Sulfite reductase hemoprotein" in Handbook of Metalloproteins, (A. Messerschmidt, R. Huber, T. Poulos, K. Wieghardt, Eds), Vol 1, pp 471-485, John Wiley \& Sons, LTD

- Ullrich, T.C., Blaesse, M., Huber, R. (2001) "Crystal structure of ATP sulfurylase from Saccharomyces cerevisiae, a key enzyme in sulphate activation", EMBO Journal, 3 , 316-329 


\section{Trabalhamos pela sua segurança...}

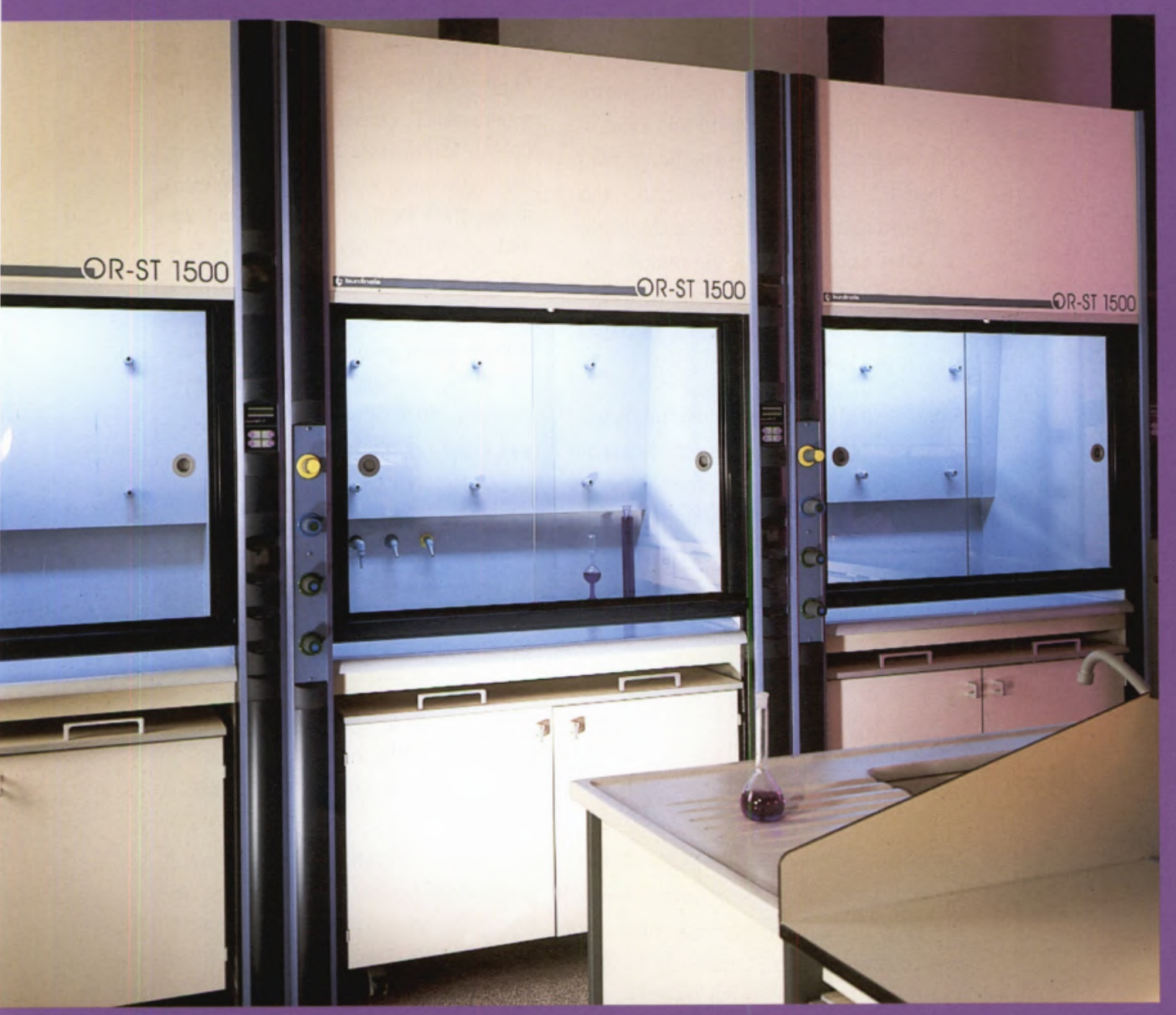

त 